\title{
Mineral Composition and Bioaccessibility in Asteracantha longifolia (L.) Nees
}

\author{
Seema R. Saple ${ }^{1}$, Sadanand E. Raval ${ }^{1 *}$ and Vikas V. Vaidya ${ }^{2}$ \\ 'Department of Chemistry, Kirti M. Doongursee College, Dadar, Mumbai - 400028, \\ Maharashtra, India; raval_sadanand@yahoo.co.in \\ ${ }^{2}$ Department of Chemistry, Royal College of Arts Science and Commerce, Mira Road, \\ Bhayandar, Thane - 401107, Maharashtra, India
}

\begin{abstract}
Asteracantha longifolia (L.) Nees. (AL) a small, spiny weed found in marshy places. It is reported for its "antitumor, hypoglycemic, aphrodisiac, antibacterial, free radical scavenging and lipid peroxidation, hepatoprotective activities"3. Accompanying its uses for a medicinal purpose the plant is also used as a leafy vegetable in some states of India. Hence study of mineral composition of Asteracantha longifolia (L.) Nees and its bioaccessibility is crucial along with studying phytoconstituents of this plant. Nutritional food value of the plant can be accessed by in-vitro gastrointestinal simulation in the form of Bioaccessible Fraction (BF). The bioaccessibility of minerals found in the plant is not investigated thoroughly, mainly in functional foods. Therefore, in this research work we have subjected shade-dried powdered material of AL to ICPAES qualitative and quantitative analysis. The results revels presence of the essential elements like Calcium (Ca) at 814.5 ppm with \%BF 96.5, Magnesium (Mg) at $169.2 \mathrm{ppm}$ with \%BF 102.8 and micronutrients like Iron (Fe) at 5.3 ppm with \%BF of 25.0, Manganese (Mn) at $4.1 \mathrm{ppm}$ with \%BF 100.9 and Zinc (Zn) at $0.6 \mathrm{ppm}$ with \%BF 31.6. Successively based on the findings it is concluded that AL has good nutritional value.
\end{abstract}

Keywords: Asteracantha longifolia (L.) Nees, Bioaccessibility, ICP-AES, Mineral Composition

\section{Introduction}

"Traditional medicines are getting important contemplation in global health care considering their vital properties of being natural, low side effects, and significant in therapeutic actions"'. With these properties, traditional medicines can go hand in hand with modern synthetic medicines to cure diseases. "The medicinal plants are comprised of different therapeutic agents, various phytoconstituents like phytosterols, fatty acids, minerals, polyphenols, proanthocyanins, mucilage, alkaloids, enzymes, amino acids, carbohydrates, hydrocarbons, flavonoids, terpenoids, vitamins, and glycosides" ${ }^{2}$. In recent times extensive research work is going on to explore the therapeutic agents, phytoconstituents of medicinal plants, bioavailability and bioaccessibility of phytoconstituents and to study the mode of therapeutic action.

"Asteracantha longifolia (L.) Nees (AL) belong to a family Acanthaceae is known as Talamkhana in Unani and Kokilasha in Ayurveda system of medicine. It is a small, spiny weed found in moist places throughout India. The plant is widely distributed in India, Srilanka, Burma and Nepal"6. "It has been found that it is used as a leafy

*Author for correspondence 
vegetable in some states of India like Odisha, Chhattisgarh and West Bengal. It has also been observed that boiled aerial parts of the succulent plant of pre-flowering and flowering stages are randomly used as haematinic by the rural people of these states" ${ }^{4,5}$. "The plant seeds, roots and leaves are used for medicinal purposes. Seeds are aphrodisiac, emmenagogue while roots and leaves are diuretic in nature" 6,7 . "The potential use of the aerial parts of $\mathrm{AL}$ as a vegetable source for human consumption is considered promising, given their high nutritional value in terms of natural minerals and trace elements, including $\mathrm{Mg}, \mathrm{Ca}, \mathrm{Mn}, \mathrm{Fe}, \mathrm{Zn}$ and $\mathrm{Cr}$, dietary fiber and bioactive compounds" $7-10$.

Due to the unavailability of precise information on mineral composition and its bioaccessibility fraction in aerial parts of $\mathrm{AL}$, we have attempted to study its proximate composition, quantitative assessment of minerals and followed by study of bioaccessibility fraction for the minerals and trace elements.

\section{Material and Method}

\subsection{Plant Collection}

Sampling of the plant material of AL from Western Ghats of Maharashtra was conducted during its flowering season of September to November months.

\subsection{Plant Material Preparation}

The AL plant material after collection was washed thoroughly and dried under shade at room temperature for 2-3 weeks carefully. The dried material was powdered, sieved (through an ASTM 80 mesh) and homogenized powder was then stored in an air-tight container.

\subsection{Chemicals and Reagents}

Hydrochloric acid, Nitric acid (65\%), and Karl Fischer reagents were purchased from Merck. Biorelavent media (FaSSIF/FeSSIF/FaSSGF powder) was purchased from Inveniolife Technology Pvt Ltd. Deionized water was obtained from a Milli-Q Plus system.

\subsection{Proximate Analysis}

Following parameters were studied for proximate analysis

- Ash values.

- Extractive values.
- Loss on drying.

- Moisture content by Karl Fischer Titration.

\subsubsection{Ash Values}

\subsubsection{Total Ash}

About 2 gm powdered sample was accurately weighed into a silica crucible. Incinerated for $3 \mathrm{hrs}$ at $600^{\circ} \mathrm{C}$, in a muffle furnace till it gets free from carbon. The sample was cooled weighed and the percentage of ash was calculated.

\subsubsection{Acid-insoluble Ash}

To the crucible from total ash, $25 \mathrm{~mL}$ of dilute $\mathrm{HCl}$ was added and boiled for 5 minutes and filtered through an ash-less filter paper. The collected insoluble matter was washed with hot water and dried carefully in the oven. The residue was then ignited to constant weight. The percentage of Acid insoluble ash was calculated against initial weight.

\subsubsection{Water-soluble Ash}

To the crucible from total ash $25 \mathrm{~mL}$ water was added and boiled for 5 minutes and filtered through an ash-less filter paper. The collected insoluble matter was washed with hot water and dried carefully in the oven. The residue was then ignited to constant weight. The weight of this residue was subtracted from the weight of Total ash and the percentage of water-soluble ash was calculated against the initial weight.

\subsubsection{Extractive Value}

\subsubsection{Water-soluble Extractive Value}

$5 \%$ aqueous solution was prepared by weighing accurately about $5 \mathrm{gm}$ powdered sample in a conical flask. The solution was allowed to stand for a day by stirring the solution from time to time. The solution was then filtered through the grade-41, Whatman filter paper. The filtrate was evaporated to dryness in a previously weighed empty evaporating dish on a water bath and the residue was discarded. The evaporating dish was weighed to calculate the water-soluble extractive value.

\subsubsection{Alcohol-soluble Extractive Value}

$5 \%$ ethanolic solution was prepared by weighing accurately about $5 \mathrm{gm}$ powdered sample in a conical flask. The solution was allowed to stand for a day by stirring the 
solution from time to time. The solution was then filtered through the grade- 41 , Whatman filter paper. The filtrate was evaporated to dryness in a previously weighed empty evaporating dish on a water bath and the residue was discarded. The evaporating dish was weighed to calculate the alcohol-soluble extractive value.

\subsubsection{Loss on Drying}

Loss of weight was calculated in percentage on about $2 \mathrm{~g}$ powdered sample at $100-105^{\circ} \mathrm{C}$ for 3 hours.

\subsubsection{Moisture Content by Karl Fischer Titration}

Percent water content was calculated for the $100 \mathrm{mg}$ powdered sample with Karl Fischer titration in specially dried Methanol and pre-neutralized Karl Fischer reagent. Calibration/ titration factor for the Karl Fischer reagent was determined with Disodium Tartrate.

\section{Mineral Composition by Inductively Coupled Plasma (ICP)-AES and Bioaccessibility}

\subsection{Sample Preparation}

About $100 \mathrm{mg}$ of powdered sample was digested for about 12 hours with $5 \mathrm{~mL}$ of nitric acid into a $25 \mathrm{~mL}$ volumetric flask. This digested solution was then diluted up to the mark with deionized water. This solution was filtered through grade-41, Whatman filter paper. The filtrate was subjected to ICP-AES to determine the mineral composition qualitatively and quantitatively.

\subsection{In-vitro Gastrointestinal Digestion and Bioaccessibility of Minerals}

Bioaccessibility of minerals was evaluated from two chronological stages of in-vitro gastrointestinal digestion system i.e. gastric digestion and intestinal digestion

\subsection{Preparation of Gastric and Intestinal Solutions ${ }^{11}$}

\subsubsection{Buffer Preparation for in vitro Gastric Digestion Solution}

In about $0.9 \mathrm{~L}$ of purified water dissolve $2 \mathrm{~g}$ of Sodium chloride $(\mathrm{NaCl})$. Adjust the $\mathrm{pH}$ to 1.6 with Hydrochloric acid $1 \mathrm{~N}$ makeup to volume $(1 \mathrm{~L})$ with purified water at room temperature.

Add $0.06 \mathrm{~g}$ of FaSSIF/FeSSIF/FaSSGF powder to about $0.5 \mathrm{~L}$ of buffer. Stir until powder is completely dissolved. Makeup to volume $(1 \mathrm{~L})$ with buffer at room temperature

\subsubsection{In-vitro Gastric Digestion}

About $200 \mathrm{mg}$ of the powdered sample was added with $50 \mathrm{~mL}$ of the gastric digestion buffer ( $\mathrm{pH}$ 1.6). The mixture was sonicated for 1-2 min for degassing and then incubated for 2 hours in a thermostatic water bath at $37^{\circ} \mathrm{C}$

\subsubsection{Buffer Preparation for in vitro Intestinal Digestion Solution}

In about $0.9 \mathrm{~L}$ of purified water dissolve $0.42 \mathrm{~g}$ of Sodium hydroxide pellets $(\mathrm{NaOH}), 3.95 \mathrm{~g}$ of Monobasic sodium phosphate monohydrate $\left(\mathrm{NaH}_{2} \mathrm{PO}_{4} \cdot \mathrm{H}_{2} \mathrm{O}\right), 6.19$ $\mathrm{g}$ of Sodium chloride $(\mathrm{NaCl})$. Adjust the $\mathrm{pH}$ to 6.5 with Sodium hydroxide $1 \mathrm{~N}$ or Hydrochloric acid $1 \mathrm{~N}$. Makeup to volume $(1 \mathrm{~L})$ with purified water at room temperature

Add $2.24 \mathrm{~g}$ of FaSSIF/FeSSIF/FaSSGF powder to about $0.5 \mathrm{~L}$ of buffer. Stir until powder is completely dissolved. Makeup to volume $(1 \mathrm{~L})$ with buffer at room temperature.

\subsubsection{In-vitro Intestinal Digestion}

About $200 \mathrm{mg}$ of the powdered sample was added with $50 \mathrm{~mL}$ of the Intestinal digestion buffer ( $\mathrm{pH}$ 6.5). The mixture was sonicated for 1-2 min for degassing and then incubated for 2 hours in a thermostatic water bath at $37^{\circ} \mathrm{C}$.

Centrifuge both the mixtures at $3000 \mathrm{rpm}$ for $30 \mathrm{~min}$ at the end of the incubation period. The supernatants were subjected to ICP-AES analysis to determine the elemental composition and bioaccessibility.

\subsection{Calculation of Bioaccessibility Fraction (\%)}

"The bioaccessible fraction is the maximum amount of a nutrient or contaminant that can be absorbed through the intestinal epithelium, reaching the bloodstream (Souza et al., 2018)"12.

"The percentage (\%) of bioaccessibility was defined as the fraction (concentration) of the element released in the in vitro digestion compared to the total amount (concentration) of the element, and the value was 
calculated according to the formula (Leufroy et al., 2012)" ${ }^{\prime 10}$ as given below:

$\%$ Bioaccesibility Fraction $=\frac{\text { Fraction of total element }}{\text { Total element concentration }} \times 100$

\section{Results and Discussion}

The proximate analysis of powdered sample includes Ash values, Extractive values, Loss on drying and Moisture content by Karl Fischer titration.

Ash value is the indication of total amount of minerals present in the sample under study. Usually it consists of inorganic components like Sodium, Potassium, Calcium and Chlorides. Determination of the ash is significant for a number of reasons like Nutritional value, Quality, Microbiological stability and processing of the material.

The mineral composition of plant material is indicated by the Ash value which includes Total ash (12.44\%), the Water-soluble (11.02\%) and the Acid-insoluble (9.03\%). The Water-soluble extractive value here was found to be higher than the Alcohol-soluble extractive value. It was found to be $16.5 \%$. It exhibits that the powdered sample has higher water-extractable constituents than the alcohol. Moisture content is also important which plays a vital role in controlling the decay of the powder sample during storage and in its formulations. Lower moisture content is advisable for higher stability. The moisture content for the plant material was $13.07 \%$. Results of proximate analysis are illustrated in Table 1.

Table 1. Proximate analysis results

\begin{tabular}{|l|l|l|}
\hline Sr. No. & Parameter & Result \\
\hline 01. & Total ash & $12.44 \% \pm 0.08$ \\
\hline 02. & Water soluble ash & $11.02 \% \pm 0.07$ \\
\hline 03. & Acid-insoluble ash & $9.03 \% \pm 0.06$ \\
\hline 04. & Water-soluble extractive & $16.5 \% \pm 0.21$ \\
\hline 05. & Alcohol-soluble extractive & $3.2 \% \pm 0.32$ \\
\hline 06. & Loss on drying & $10.75 \% \pm 0.12$ \\
\hline 07. & Moisture content & $13.07 \% \pm 0.05$ \\
\hline
\end{tabular}

\subsection{Mineral Composition and Bioaccesibility}

A qualitative and quantitative analysis was performed with ICP-AES for elements of Asteracantha longifolia (L.) Nees. Results of the analysis are illustrated in Table 2. The elements Aluminum (Al), Calcium (Ca), Cobalt (Co), Iron $(\mathrm{Fe})$, Magnesium $(\mathrm{Mg})$, Manganese $(\mathrm{Mn})$ and Zinc $(\mathrm{Zn})$ were detected and quantitatively measured for their bioaccessibility as observed in the table given below.

Calibration curve was plotted for response of the element against the predetermined concentrations. The correlation coefficient of 0.99 is indicative of good agreement between response and concentration for each element.

Table 2. Qualitative and Quantitative analysis results

\begin{tabular}{|l|l|l|l|}
\hline $\begin{array}{l}\text { Sr. } \\
\text { No. }\end{array}$ & Element & $\begin{array}{l}\text { Conc. found } \\
\left(\boldsymbol{\mu g ~ g}^{-1}\right)\end{array}$ & \% Bioaccesibility \\
\hline 01 & Aluminum $(\mathrm{Al})$ & 9.4 & 9.3 \\
\hline 02 & Calcium $(\mathrm{Ca})$ & 814.5 & 96.5 \\
\hline 03 & Cobalt $(\mathrm{Co})$ & 0.1 & 83.3 \\
\hline 04 & Iron $(\mathrm{Fe})$ & 5.3 & 25.0 \\
\hline 05 & Magnesium $(\mathrm{Mg})$ & 169.2 & 102.8 \\
\hline 06 & Manganese $(\mathrm{Mn})$, & 4.1 & 100.9 \\
\hline 07 & Zinc $(\mathrm{Zn})$ & 0.6 & 31.6 \\
\hline
\end{tabular}

Calcium (Ca) is found to have a \%BF of 96.5 and Magnesium (Mg) has a \%BF of 102.9 "Calcium and Magnesium plays essential role in plants as well as human body. Calcium in plant is important in formation of and stability of cell walls and in maintenance of membrane structure and permeability, activates some enzymes, regulates many responses of cells to stimuli, in human calcium functions as a constituent of bones and teeth, regulation of nerve and muscle function. In blood coagulation, calcium activates the conversion of prothrombin to thrombin and also takes part in milk clotting"13.

"Magnesium is a vital component of chlorophylls, activates many enzyme and deficiency of Magnesium lead to poor growth, decreased muscle tone, ataxia, progressive in coordination and convulsions"13.

The micronutrients or trace elements are present in very small quantities. Iron $(\mathrm{Fe})$ has $\% \mathrm{BF}$ of 25.0, Manganese $(\mathrm{Mn})$ and Zinc $(\mathrm{Zn})$ are having \%BF of 100.9 and 31.6 respectively. "Iron is a component of cytochromes, electron transport, activates some enzymes, plays a role in chlorophyll synthesis in plants and Iron functions as hemoglobin in the transport of oxygen, In cellular respiration, it functions as an essential component of enzymes involved in biological oxidation" ${ }^{13}$ in the human body. 
"The \% bioaccessibility is the absorbed nutrient which plays a vital role in routine physiological functions. Factors affecting bioaccessibility are the elemental oxidation state and its adherence with the food matrix i.e. its interactions with food components" 10 .

\section{Conclusion}

The results of mineral composition, mineral concentration and \% bioaccessibilityderived from in-vitro gastrointestinal digestion of Asteracantha longifolia (L.) Nees reveals that the plant is a rich source of essential elements like Calcium $(\mathrm{Ca})$, Iron ( $\mathrm{Fe})$, Magnesium $(\mathrm{Mg})$ and Manganese $(\mathrm{Mn})$ with a considerable amount of bioaccessibility. This indicates that the plant has good nutritional value.

\section{Acknowledgement}

1. Blatter Herbarium, St. Xavier's College, Mumbai, India.

2. Sophisticated Analytical Instrument Facility (SAIF) IIT Bombay.

\section{References}

1. Tilburt JC, Kaptchuk TJ. Herbal medicine research and global health: An ethical analysis.

2. Kshirsagar $\mathrm{AD}$, Ingale $\mathrm{KG}$, Vyawahare NS, Thorve VS. Hygrophila spinosa: A comprehensive review. Pharmacognosy Review. 2010; 4(8):167-PMid: 22228957 PMCid: PMC32499 https://doi.org/10.4103/09737847.70912

3. Chauhan NS, Dixit VK. Asteracantha longifolia (L.) Nees, Acanthaceae: Chemistry, traditional, medicinal uses and its pharmacological activities - A review. Brazilian Journal of Pharmacognosy. 2010; 20(5):812-https://doi.org/10.1590/ S0102-695X2010005000022
4. Dash AK, Dutta GK, Sardar KK, Sahoo S. Ethnomedicinal importance of Hygrophila Spinosa T. anders: A review. Plant Archives. 2012; 12(1):5-9.

5. Dash AK, Dutta GK, Sahoo G, Maity A, Sardar KK, Panda MK. HPLC-MS and HPTLC Finger printing of fractions of Asteracantha longifolia Leaf extract. International Journal of Chemical Studies. 2018; 6(3):1767-74.

6. Pandey HS, Pandey RP. Isolation and characterization of Betuline from Asteracantha longifolia (L.) Nees. International Journal of Current Research. 2017 Feb; 9(02):46574-5.

7. Sarvananda L, Premarathna AD. Ethnopharmacolological potential and medicinal uses of Hygrophila auriculata. Journal of Ayurvedic and Herbal Medicine. 2018;4(4):185-8. https://doi.org/10.31254/jahm.2018.4408

8. Dash AK, Dutta GK, Sahoo G, Mishra SK, Sardar KK, Bisoi PC. Phytochemical screening, mineral and proximate composition of Asteracantha longifolia leaf extracts as a quality livestock feed. Journal of Medicinal Plants Research. 9 June, 2020; 6(21): 3786-3792. https://doi.org/10.5897/ JMPR12.347

9. Dash AK, Dutta GK, Sahoo GA, Sardar KK, Mishra SK. Nutri-biochemical composition of Asteracantha longifolia. Medicinal Plants. 2015 Sep; 7(3):233-6.

10. Bertina RL, Maltez HF, de Gois JS, Borges DLG, da Silva Campelo Borges G, Gonzaga LV, Fett R. Mineral composition and bioaccessibility in Sarcocornia ambigua using ICP-MS. Journal of Food Composition and Analysis. 2016; 47 (2016): 45-51. https://doi.org/10.1016/j.jfca.2015.12.009

11. FaSSIF, FeSSIF, FaSSGF, InterBio Tech. https://www.interchim.fr/ft/1/1A7101.pdf

12. do Prado Ferreiraa M, Tarley CRT. Assessment of in vitro bioacessibility of macrominerals and trace elements in green banana flour. Journal of Food Composition and Analysis. 2020 Sep; 92:1035 https://doi.org/10.1016/j. jfca.2020.103586

13. Soetan KO, Olaiya CO, Oyewole OE The importance of mineral elements for humans, domestic animals and plants: A review. African Journal of Food Science. 2010 May; 4(5):200-22. 